\title{
次世代自動車のための高摩擦・低相手攻撃性ブレーキパッドの開発
}

\section{Development of high friction and low aggressiveness brake pad for next-generation automobile}

\author{
○学 炭䇫 美穂 (名古屋大) 正 梅原 徳次 (名古屋大) \\ 正上坂 裕之 (名古屋大) 正 野老山 貴行 (名古屋大)
}

Miho SUMIGAMA, Noritugu UMEHARA, Hiroyuki KOUSAKA, Takayuki TOKOROYAMA, Nagoya University, Furo-cho, Chikusa-ku, Nagoya 464-8603, Japan

Key Words: Abrasive, Wear, Friction, Brake pad, Automobile

\section{1. 諸言}

自動車の最重要部品の一つであるディスクブレーキは, ブ レーキパッド及びディスクロータの間に発生する摩擦によ つて制動力を得ており, 過酷かつ複雑な摩擦環境において使 用されるしゅう動部品である.

ブレーキパッドに求められる性能は日本と欧州で異なり， 日本では低ブレーキノイズ, 高寿命などが重視されるが, 欧 州では効きの良さが重視される.しかし，近年日本において もブレーキの効きの良さが求められている(1). また，日欧共 通のニーズとして自動車の燃費向上を目的とした自動車部 品の軽量化が求められている(2). 軽量化の手法としては耐摩 耗性を有するディスクロータ材質の選定によるディスクロ 一タの肉薄化や, 高摩擦材料を含有させたブレーキパッド材 質の選定によるブレーキシステム全体の小型化などがある (3).このような要求を満たすためには高摩擦かつ低相手攻撃 性を有するブレーキパッドの開発が必要である.

ブレーキパッドは高摩擦かつ低相手攻撃性以外にも, 低ブ レ一キ鳴き, 複雑な摩擦条件下における摩擦係数の安定性な ど様々な性能が求められるため, 結合剤, 研削剤（アブレシ ブ)，充填剤，緘維，潤滑剤など多様な材料で構成されてい る. 複雑な構成であるため, ブレーキパッドの理論的な設計 手法は確立されておらず，実験データに基づく経験的設計手 法に頼らざるを得ない. そこで本研究では主要材料であるア ブレシブに注目し，高摩擦かつ低相手攻撃性を有するブレー キパッドの理論的な設計手法について検討した.

アブレシブの摩擦摩耗特性に関する従来の研究では, 1961 年に J.Goddard らによって球, 四角錐, 三角錐及び円錐の摩 擦係数の掘り起し項のモデル式が提案されている ${ }^{(4)} .1988$ 年 には堀切川らによってアブレシブ摩耗の形態遷移マップが 提案されている(5). また, S.Jacobson らは MEMS 技術を用い て多数のアブレシブが配列する面を作製し, 多数のアブレシ ブが摩擦摩耗に及ぼす影響を調べている( ${ }^{(6)}$.

本研究ではこのような従来のアブレシブ理論を用いてブ レーキパッドモデルを作製し, 高摩擦かつ低相手攻撃性を示 すアブレシブ条件を予測, スクラッチ試験によるモデルの実 証を行った.

\section{2. ブレーキパッドモデルの作製及び解析}

\section{1 提案するブレーキパッドモデル}

結合剂及びアブレシブから成るブレーキパッドモデルを 図 1 に提案する. 結合剂の摩擦係数の凝着項 $\mu_{\mathrm{a}}$ は 0.5 である と仮定した.また，アブレシブは均一に配列しており，この アブレシブの配列は摩擦摩耗特性に影響を及ぼさないと仮 定した.

アブレシブには表 1 に示す 4 種類の “すい”を用いた．た だし(a)Corner first pyramid(CFP)及び(b)Face first pyramid(FFP) の形状は等しく，異なる方向へしゅう動する場合にはそれぞ れ区別して扱う. 次に(c)Anisotropic pyramid direction1(AP1)

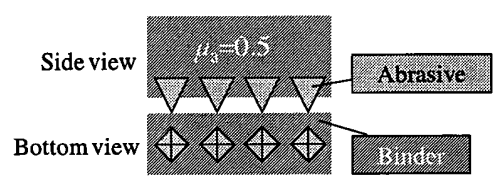

Fig. 1 Schematic image of suggested brake pad model

Table 1 Abrasive shapes of brake pad model

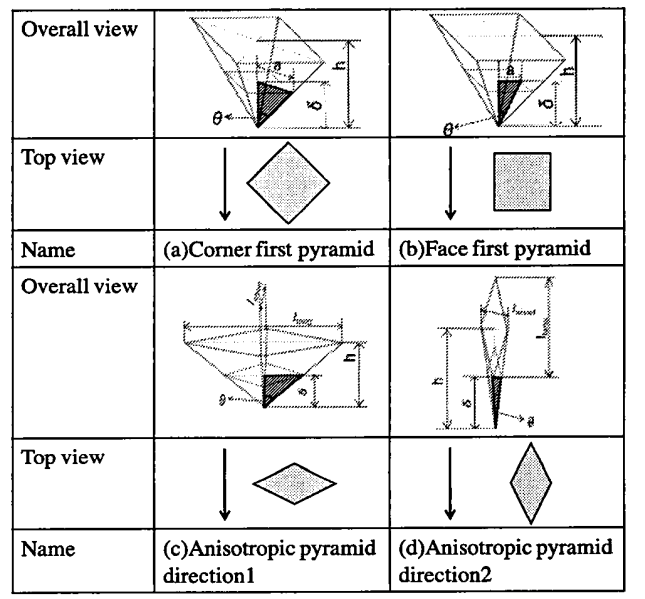

及び(d)Anisotropic pyramid direction2(AP2)も同様である. 本研 究ではアブレシブをしゅう動させる方向の投影面の先端角 を先端突起角 $\theta$ と定義した. また, 異方性アブレシブの偏平 率 $\beta$ を(1)式のように定義した. $l_{\text {long }}$ は底面の長い対角線の長 さを表し， $l_{\text {short }}$ は底面の短い対角線の長さを示す.

$$
\beta=\frac{l_{\text {short }}}{l_{\text {long }}}
$$

\section{2 摩擦係数 $\mu$ 及び摩耗係数 $K$ のモデル式}

ブレーキパッドモデルの摩擦係数 $\mu$ は(2)式で表されると 仮定した.ここで, $\mu_{\mathrm{p}}$ は摩擦係数の掘り起し項, $\mu_{\mathrm{a}}$ は摩擦係 数の凝着項, $\alpha$ は掘り起し項の凝着項に対する比である. $\mu_{\mathrm{p}}$ は(3)式のように表される(7). ここで $A_{\mathrm{h}}$ 及び $A_{\mathrm{n}}$ はアブレシブ のディスクロータに食い込んでいる部分の水平投影面積及 び垂直投影面積である。一方， $\mu_{\mathrm{a}}$ は 0.5 であると仮定した.

また, ブレーキパッドモデルの摩耗係数 $K$ は(4)式で表さ れると仮定した. ここで $f_{\mathrm{ab}}$ は摩耗度である. $f_{\mathrm{ab}}$ は堀切川ら によって提案された無次元パラメータであり，0から 1 の間 で変化する ${ }^{(5)}$. 堀切川らは $f_{\mathrm{ab}}$ の変化に伴って摩耗形態が ploughing, wedge 及び cutting に変化することを明らかにして いる. また, この $f_{\mathrm{ab}}$ は堀切川らによってアブレシブのすく い角に依存することが報告されているが, 他の因子が $f_{\mathrm{ab}}$ に 及ぼす影響については解明されていない. そこで, $f_{\mathrm{ab}}$ は図 2 に示すアブレシブの開き角 $\varphi$ に比例すると仮定し, $f_{\mathrm{ab}}$ を(5) 式のような先端突起角 $\theta$ 及び $\varphi$ の関数で表した. 


$$
\begin{gathered}
\mu=\alpha \mu_{\mathrm{p}}+(1-\alpha) \mu_{\mathrm{a}} \\
\mu_{\mathrm{p}}=2 \frac{A_{\mathrm{h}}}{A_{\mathrm{n}}} \\
K=\alpha f_{\mathrm{ab}} \mu_{\mathrm{p}} \\
f_{\mathrm{ab}}=\left(-\frac{1}{36864\left(\frac{1}{\tan \theta}\right)^{6}+1}+1\right) \cdot \frac{\varphi}{90}
\end{gathered}
$$

\section{3 ブレーキパッドモデルの解析結果}

掘り起し項の凝着項に対する比 $\alpha$ を 0.5 とし, 異方性アブ レシブの偏平率 $\beta$ を 0.5 とした場合の, 先端突起角 $\theta$ 及び開 き角 $\varphi$ の摩耗係数 $K$ 及び摩擦係数 $\mu$ の比 $K / \mu$ に及ぼす影響を 調べた. $\theta$ は $10^{\circ}$ から $80^{\circ}$ まで変化させ, $\varphi$ は $8.2^{\circ}$ ((d)AP2), $45^{\circ}$ ((a)CFP), $82^{\circ}$ ((c)AP1), $90^{\circ}$ ((b)FFP)と変化させた. 解 析結果を図 3 に示す. ただし図 3 に示す $K / \mu$ は小さい值を示 す程, 高摩擦かつ低相手攻撃性である。

図3に示すように $\theta$ の増加に伴って $K / \mu$ は減少した.また, $\theta$ が小さい領域では開き角 $\varphi$ の増加に伴って $K / \mu$ は増加した. $\theta$ が大きい領域では AP1, FFP, CFP, AP2 の順に $K / \mu$ が減少 した.

\section{3. スクラッチ試験によるモデルの実証}

\section{1 実験方法}

図 3 に示す結果を定量的に実証するために開き角 $\varphi$ をパラ メータとして単一圧子を用いてスクラッチ試験を行った. 摩 擦係数は動ひずみ計を用いて測定した. 摩耗度 $f_{\mathrm{ab}}$ 及び摩耗 係数 $K$ はスクラッチ試験後にスクラッチ痕断面を AFM で測 定し算出した. スクラッチ試験装置を図 4 に示す. 単一圧子 にはビッカース圧子及びヌープ圧子を用いた. 各圧子の特性 及び SEM 画像を表 2 及び図 5 に示す. 表 2 に示すように各 圧子の $\varphi$ は $8.2^{\circ}$ ((d)AP2), $45^{\circ}$ ((a)CFP), $82^{\circ}$ ((c)AP1), 90 ((b)FFP)である. ビッカース圧子及びヌープ圧子の幾何学的 特性からアブレシブの先端突起角 $\theta$ を統一してスクラッチ試 験を行うことは不可能であるため, 試験結果を補正する必要 がある. 試験結果の補正には，円錐型のダイヤモンド圧子を 用いて, $\theta$ をパラメータとして行ったスクラッチ試験の結果 を用いた. $\theta$ が摩耗係数 $K$ 及び摩擦係数 $\mu$ の比 $K / \mu$ 及び摩耗 度 $f_{\mathrm{ab}}$ に及ぼす影響を図 6(a)及び(b)に示す，図 6 に示すよう に最小二乗近似を用いて線形近似を行った.この線形近似が 全ての $\theta$ において可能であるとして補正を行った. この補正 によって $\theta$ は $65^{\circ}$ で統一した. また, 他の実験条件は表 3 に示す.

Table 2 The properties of the indenters

\begin{tabular}{|c|c|c|c|c|c|c|}
\hline Indenter & - & - & Vickers & \multicolumn{2}{c|}{ Knoop } \\
\hline Material & - & - & Diamond & Diamond \\
\hline Name & - & - & CFP & FFP & AP1 & AP2 \\
\hline Cone angle & $\theta$ & - & 74 & 66 & 86 & 65 \\
\hline Radius & - & $\mu \mathrm{m}$ & \multicolumn{4}{|c|}{$<<1$} \\
\hline
\end{tabular}

Table 3 Experimental condition

\begin{tabular}{|c|c|c|c|}
\hline The ratio of $\mu \mathrm{p}$ to $\mu \mathrm{a}$ & $\alpha$ & - & 1 \\
\hline Penetration depth & $\delta$ & $\mu \mathrm{m}$ & 1 \\
\hline Namber of cycles & - & - & 3 \\
\hline Disc & - & - & SUS304 \\
\hline
\end{tabular}

Sliding direction

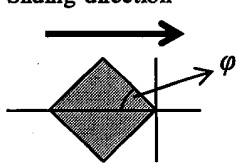

Fig. 2 Schematic image of open angle $\varphi$ of abrasive

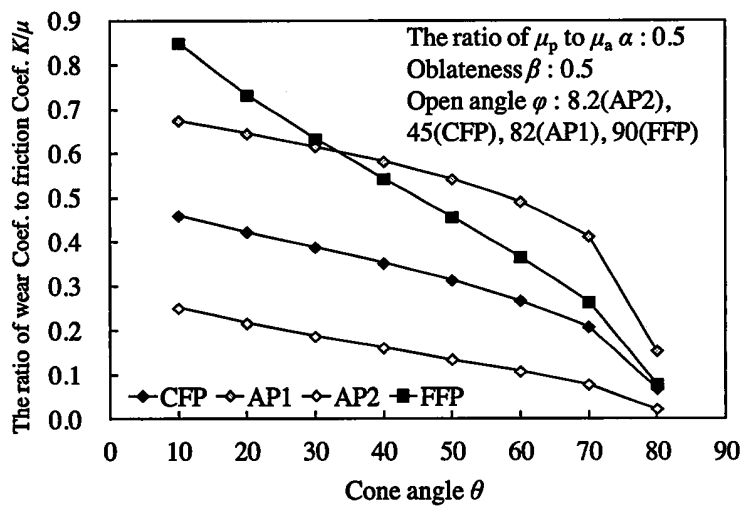

Fig. 3 The influence of cone angle $\theta$ and open angle $\varphi$ to the ratio of wear coefficient to friction coefficient $K / \mu$

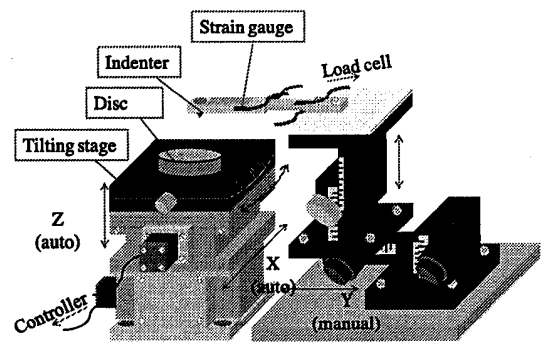

Fig. 4 Outside overview of scratch tester

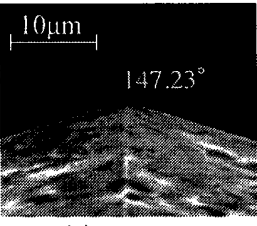

(a)

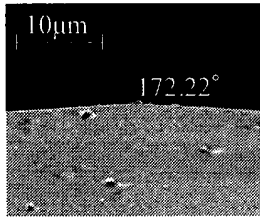

(c)

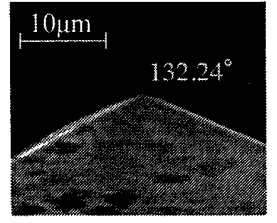

(b)

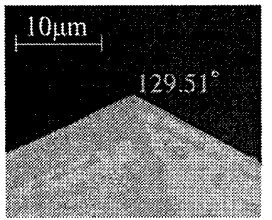

(d)
Fig. 5 The SEM images of the indenters (a)CFP, (b)FFP, (c)AP1 and (d)AP2

\section{2 実験結果}

開き角 $\varphi$ が摩擦係数 $\mu$ に及ぼす影響及び $\varphi$ が摩耗係数 $K$ 及び $\mu$ の比 $K / \mu$ に及ぼす影響を図 7(a)に示す.また $\varphi$ が摩耗 度 $f_{\mathrm{ab}}$ に及ぼす影響を図 7(b)に示す.

図 7(a)に示すように AP1，CFP，FFP，AP2 の順に $\mu$ 及び $K / \mu$ が減少した。これは図 3 に示すモデルの解析と一部異な った。 モデルでは FFP は CFP より大きな $K / \mu$ を示した.ま た，図 7(b)に示すように AP1，FFP，CFP，AP2 の順に $f_{\mathrm{ab}}$ が 減少した.これも一部モデルと異なった. モデルでは $f_{\mathrm{ab}}$ は $\varphi$ に比例すると仮定したため, FFP が最も大きな $f_{\mathrm{ab}}$ を示した. 

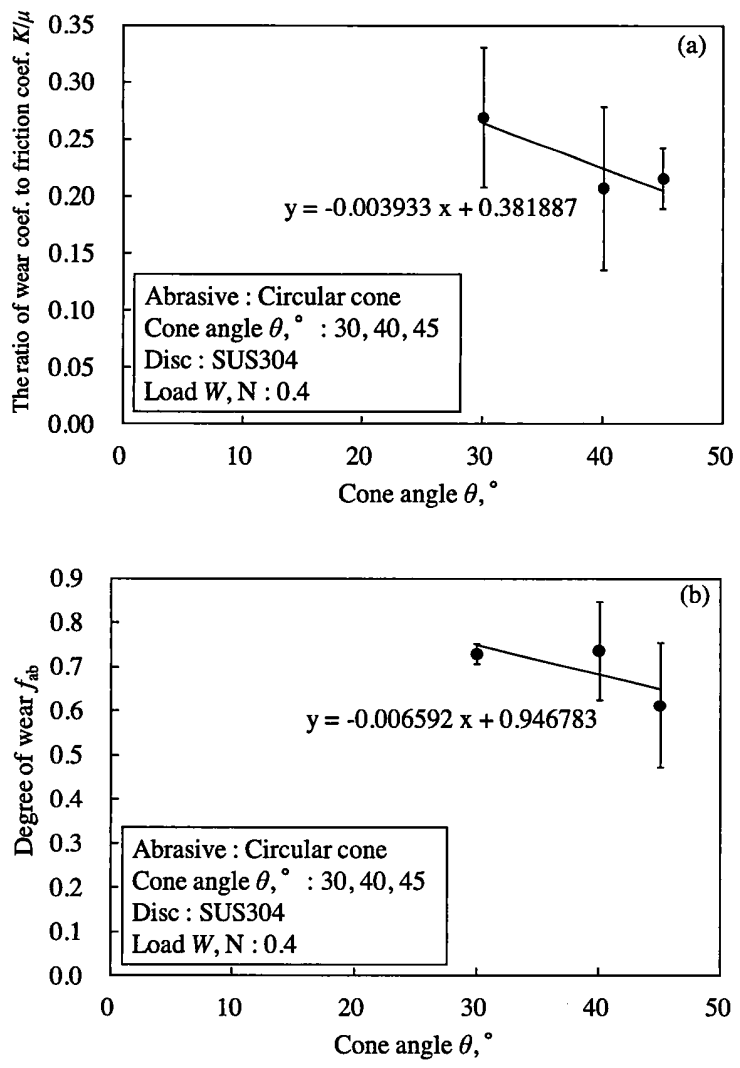

Fig. 6 The influence of cone angle $\theta$ to (a) the ratio of wear coefficient to friction coefficient $K / \mu$ and (b) degree of wear $f_{\mathrm{ab}}$
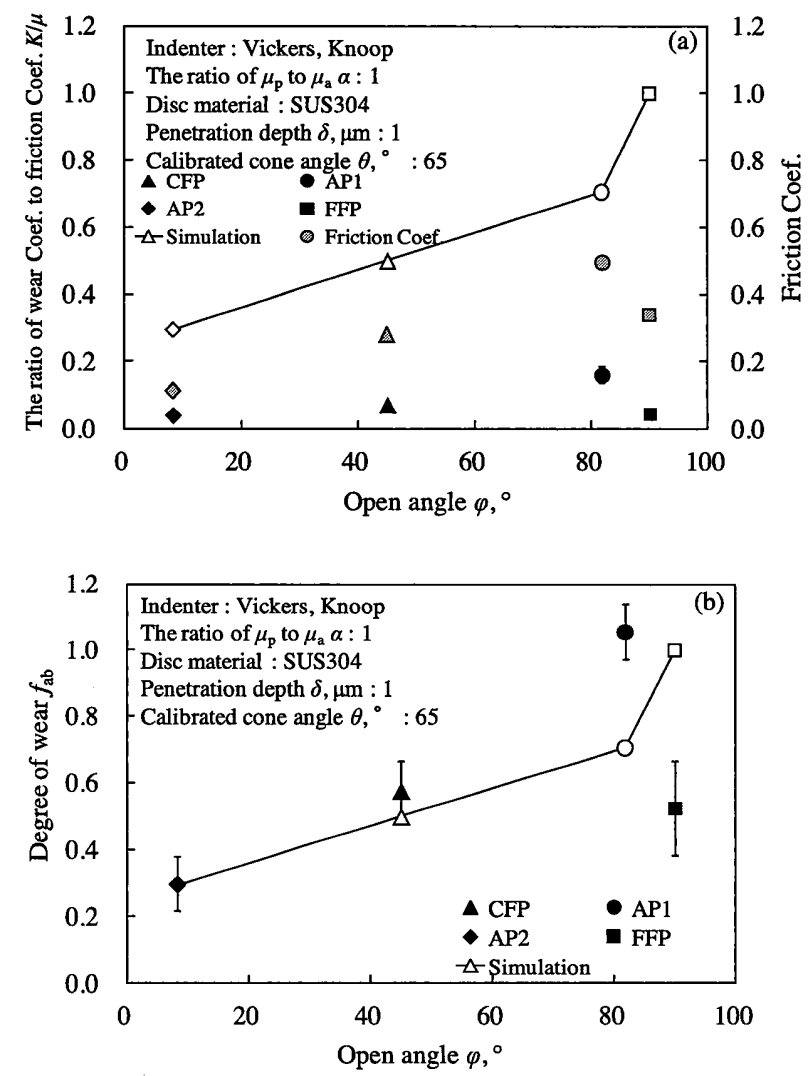

Fig. 7 The influence of open angle $\varphi$ to (a) friction coefficient $\mu$ and the ratio of wear coefficient to friction coefficient $K / \mu$ and (b) degree of wear $f_{\mathrm{ab}}$

\section{4. 考察}

図 7(a)に示すようにAP2のように開き角 $\varphi$ が非常に小さい アブレシブは高摩擦かつ低相手攻撃性を示すことが明らか になった.これは $\varphi$ が小さいアブレシブは摩耗度 $f_{\mathrm{ab}}$ が小さ いことに起因していると考えられる．また，図 7(a)及び(b) に示すように FFP の $K / \mu$ 及び $f_{\mathrm{ab}}$ がモデル解析と異なり小さ な值であったことの原因としては摩耗形態の変化が考えら れる. 堀切川らによって他の摩耗形態と比較して cutting mode では摩擦係数が小さいことが報告されているため, AP2, CFP, AP1 は ploughing または wedge であるが, FFPのみ cutting であると考えられる(5).

$\varphi$ の減少に伴う $f_{\mathrm{ab}}$ の減少は傾斜切削理論を用いて定性的 に説明することが可能である. 臼井らによって $\varphi$ の増加に伴 う切りくずの流出角度 $\eta$ の増加が報告されている ${ }^{(8)} . \varphi$ が小 さいときは完全切りくずが排出され， $\varphi$ が増加すると不完全 切りくずが排出されるようになり, やがて十分 $\varphi$ が増加する と切りくずは “うね”となって摩耗痕の両側に蓄積される. しかしこの現象を定量的に評価したモデル式はなく,未だ詳 しい原理は解明されていない.

\section{5. 結論}

(1)結合剤及びアブレシブから成るブレーキパッドモデルを 仮定し, 従来のアブレシブ理論に掘り起し項の凝着項に対す る比 $\alpha$ 及び開き角 $\varphi$ を導入し，摩擦係数 $\mu$ 及び摩耗係数 $K$ のモデル式を作製した. 作製したブレーキパッドモデルを解 析し，アブレシブの $\varphi$ の減少に伴って $K / \mu$ が減少した.

(2) ビッカース圧子及びヌープ圧子を用い, 開き角 $\varphi$ を変化さ せてスクラッチ試験を行った結果，AP2，CFP，AP1 におい て解析及び実験の結果が整合した。

(3) AP1，CFP，AP2 において解析及び実験の結果が整合した ため, 開き角 $\varphi$ の摩擦係数 $\mu$ 及び摩耗係数 $K$ の比 $K / \mu$ に及ぼ す影響を示した. $\varphi$ の増加に伴って $K / \mu$ は増加した.

\section{6. 文献}

(1)H.Fujikawa, T.Tanaka, Trend of recent technology and standardization of evaluation methods for disk brake pads, トラ イボロジスト, Vol. 53 No. 8 (2008) P512-517

(2)K.Fukizawa, S.Koike, K.Shibata, Technical trend of automotive material for weight reduction, まてりあ, Vol. 39 No. 1 (2000) P17-24

(3)Y.Hara, M.Bandai, H.Morozumi, H.Nakanishi, S.Suzuki, High friction coefficient disc pads for automotive brakes, 日立化成テ クニカルレポート, No. 41 (2003) P4548

(4)J.Goddard, H.Wilman, A Theory of friction and wear during the abrasion of metals, Wear5 (1962) P114-135

(5)K.Hokkirigawa, K.Kato, An experimental and theoretical investigation of ploughing, cutting and wedge formation during abrasive wear, TRIBOLOGY international, Vol. 21 No.1 (1988) P51-57

(6)L.Hammerstrom, S.Jacobson, Designed high-friction surface Influence of roughness and deformation of the counter surface, Wear246 (2008) P807-814

(7)J.Halling, Principles of tribology, Scholium Intl, P86-87

(8) E.Usui, M.Inoue, Plasticity analysis of cutting process with abrasive grain 1st report, 精密機械, Vol. 44 No. 8 (1977) P78-84 